JPPKMI 2 (2) (2021)
JURNAL PENELITIAN DAN PENGEMBANGAN
KESEHATAN MASYARAKAT INDONESIA
Jttps://journal.unnes.ac.id/sju/index.php/jppkmi

\title{
Efek Bullying, Kekerasan Fisik, dan Kekerasan Seksual terhadap Gejala Depresi pada Pelajar SMP dan SMA di Indonesia: Analisis Data Global School-Based Student Health Survey Indonesia 2015
}

\author{
Cindy Nur Khaliza ${ }^{1} \bowtie$, Besral $^{1}$, Iwan Ariawan ${ }^{1}$, Herlina J. EL-Matury ${ }^{2}$
}

${ }^{1}$ Fakultas Kesehatan Masyarakat, Universitas Indonesia, Depok, Jawa Barat, Indonesia

${ }^{2}$ Institut Kesehatan Deli Husada Deli Tua, Sumatera Utara, Indonesia

\begin{abstract}
Info Artikel
Sejarah Artikel:

Diterima Desember 2021

Disetujui Desember 2021

Dipublikasikan Desember 2021

Keywords:

Bullying, Physical Violence, Sexual Violence, Depressive Symptoms, Middle and High School Students

URL:

https://iournal.unnes.ac. d/sju/index.php/ippkmi Larticle/view/53149

Abstrak

Salah satu penyakit yang menjadi beban terbesar di kalangan remaja adalah depresi. Riskesdas 2018 melaporkan prevalensi depresi kelompok umur 15-24 tahun 6,2\%, kelompok umur 25-34 tahun 5,4\%. Tujuan penelitian ini untuk mengetahui efek bullying, kekerasan fisik, dan kekerasan seksual terhadap gejala depresi pada pelajar SMP dan SMA di Indonesia. Analisis data sekunder dari Global School-Based Student Health Survey Indonesia 2015 dengan desain cross sectional dan sampel sebanyak 8.517 pelajar SMP dan SMA di Indonesia. Hasil penelitian menunjukkan sebesar 20,7\% pelajar SMP dan SMA tahun 2015 di Indonesia mengalami gejala depresi. Sebesar $18.5 \%$ pelajar pernah mengalami bullying, $29.4 \%$ pernah mengalami kekerasan fisik, dan $3.1 \%$ pernah mengalami kekerasan seksual. Remaja yang pernah mengalami bullying, kekerasan fisik, dan kekerasan seksual berisiko lebih tinggi untuk mengalami gejala depresi. ORa bullying sebesar 2.5 (95\%CI 2.1-3.0), ORa kekerasan fisik sebesar 2.1 (95\%CI 1.8-2.4), dan ORa kekerasan seksual sebesar 1.8 (95\%CI 1.4-2.3). Faktor lain pada pelajar yang berisiko tinggi untuk mengalami gejala depresi adalah jenis kelamin perempuan (ORa 1.9, 95\%CI 1.72.2), pendidikan SMA (ORa 2.1, 95\% CI 1.6-2.6), minum alkohol (ORa 1.7, 95\%CI 1.3-2.1), dan merokok (ORa 1.6, 95\%CI 1.2-2.0). Disarankan kepada Kementerian Pendidikan agar menerapkan sekolah ramah anak untuk mengurangi peristiwa bullying dan kekerasan fisik atau seksual, yang dapat berisiko menimbulkan gejala depresi pada pelajar SMP dan SMA, terutama perempuan.

\section{Abstract}

One of the biggest burdens among teenagers is depression. Riskesdas 2018 reported the prevalence of depression aged group 15 24 years $6.2 \%$, age group $25-34$ years $5.4 \%$. The purpose of this study was to find out the effects of bullying, physical violence, and sexual violence on depressive symptoms in middle and high school students in Indonesia. Analysis of secondary data from the Global School-Based Student Health Survey Indonesia 2015 with cross sectional design and a sample of 8,517 middle and high school students in Indonesia. The results showed that 20.7\% of middle and high school students in 2015 in Indonesia experienced symptoms of depression. $18.5 \%$ of students had experienced bullying, $29.4 \%$ had experienced physical violence, and $3.1 \%$ had experienced sexual violence. Adolescents who have experienced bullying, physical violence, and sexual violence are at higher risk for experiencing depressive symptoms. Bullying 2.5 (95\%CI 2.1-3.0), physical violence 2.1 (95\%CI 1.8-2.4), and ORa sexual violence by 1.8 (95\%CI 1.4-2.3). Other factors in students at high risk for depressive symptoms are female sex (ORa 1.9, 95\%CI 1.7-2.2), high school education (ORa 2.1, 95\%CI 1.6-2.6), drinking alcohol (ORa 1.7, 95\%CI 1.3-2.1), and smoking (ORa 1.6, 95\%CI 1.2-2.0). It is recommended to the Ministry of Education to implement child-friendly schools to reduce the event of bullying and physical or sexual violence, which can risk causing symptoms of depression in middle and high school students, especially women.
\end{abstract}

Alamat korespondensi:

Fakultas kesehatan masyarakat, Pondok Cina,

Kecamatan Beji, Kota Depok, Jawa Barat 12345 


\section{PENDAHULUAN}

Depresi adalah penyakit mental yang umumnya ditandai dengan gejala perasaan kesepian, hilangnya minat pada suatu hal, energi berkurang, merasa rendah diri, perasaan cemas, sulit tidur di malam hari, dan kurang konsentrasi (WHO, 2017a). Depresi merupakan salah satu penyakit kesehatan mental yang menjadi beban terbesar di kalangan remaja (WHO, 2016). Tahun 2015 sebanyak 18,4\% penduduk dunia hidup dengan depresi, angka ini cukup tinggi di Asia Tenggara yakni sebanyak 27\% (WHO, 2017a).

Masa remaja dengan rentang umur antara 10 sampai 19 tahun yang merupakan fase transisi dari anak menjadi dewasa (WHO, 2017b). Masa remaja merupakan proses pembentukan jati diri seseorang. Remaja sangat rentang terhadap permasalahan kesehatan. Salah satu permasalahan kesehatan remaja yaitu kesehatan mental. Masalah kesehatan mental atau depresi dapat menyebabkan perubahan perilaku di rumah ataupun sekolah (Rahayu, 2017). Perubahan perilaku akibat depresi ini yang perlu diketahui oleh orang tua ataupun guru. Remaja yang mengalami depresi merupakan hal yang serius apabila tidak ditangani segera akan menyebabkan remaja melakukan bunuh diri (EL-Matury, 2018).

Hasil Riskesdas 2013 dan 2018 menyatakan penduduk usia 10 tahun keatas yang mengalami gangguan mental emosional yang memiliki gejala kecemasan dan depresi meningkat dari 6\% (2013) menjadi 9,8\% (2018). Hasil Riskesdas 2018 juga melaporkan kelompok umur remaja 15--24 tahun memiliki prevalensi depresi lebih tinggi (6,2\%) dibandingkan kelompok umur dewasa muda 25-34 tahun (5,4\%). Di provinsi Daerah Istimewa Yogyakarta, sekitar 3-6\% anak usia sekolah atau remaja mengalami depresi berat. Depresi berat tersebut dapat menyebabkan perilaku bunuh diri pada remaja (Indarto, 2017).

Banyak faktor risiko yang dapat mempengaruhi kejadian depresi pada usia remaja hingga dewasa. Penelitian yang dilakukan oleh Saputri (2020) telah mengidentifikasi faktor risiko depresi diantaranya adalah kecerdasan emosional, ekonomi keluarga, lingkungan keluarga (struktur keluarga, pola asuh, dan konflik), lingkungan sekolah, tekanan yang dialami setiap hari, premature, depresi ibu, dan waktu tidur. Sedangkan Peltzer (2018) menyatakan faktor risiko depresi yaitu usia, jenis kelamin perempuan, status pernikahan, status ekonomi kurang, hormon yang kurang stabil, memiliki religius yang kurang, kurangnya dukungan sosial, peristiwa kehidupan yang penuh tekanan atau traumatis (kekerasan seksual dan pelecehan fisik pada anak) dan perilaku berisiko kesehatan (merokok, durasi tidur yang tidak teratur, asupan garam yang meningkat, jarang makan, penggunaan internet yang berlebihan, dan mengalami cedera). Selain itu, memiliki penyakit kronik dan obesitas, merupakan faktor risiko depresi pada orang dewasa (Widakdo, 2013; Pereira, 2017).

Beberapa penelitian telah dilakukan untuk menilai efek bullying terhadap prestasi belajar dan kesehatan mental pada pelajar. Belum ada penelitian yang mengidentifikasi efek bullying, kekerasan fisik, dan kekerasan seksual terhadap gejala depresi pada pelajar SMP dan SMA di Indonesia. Penelitian ini bertujuan untuk mengetahui efek bullying, kekerasan fisik, dan kekerasan seksual terhadap gejala depresi pada remaja SMP dan SMA di Indonesia.

\section{METODE}

Penelitian cross sectional ini menggunakan data sekunder dari survei Kesehatan Berbasis Sekolah di Indonesia (Global School-Based Student Health Survey/GSHS) tahun 2015. Yang dapat diakses dari website https://extranet.who.int/ncdsmicrodata/index. $\mathrm{php} / \mathrm{catalog} / 489$. Populasi penelitian ini adalah anak sekolah SMP dan SMA di Indonesia. Sedangkan sampel sebanyak 8,517 anak sekolah 
SMP dan SMA negeri dan swasta dari 26 Provinsi dan $68 \mathrm{Kota} / \mathrm{Kabupaten}$ di Indonesia.

Pemilihan sampel GSHS menggunakan metode two stage cluster random sampling sampling. Tahap pertama memillih 75 SMP dan SMA di Indonesia secara Probability Proportional to Size (PPS). Tahap kedua memilih 2 kelas di sekolah terpilih secara sistematik random sampling. Semua siswa di kelas terpilih (11,917 siswa) diwawancarai sebagai responden.

Variabel outcome penelitian ini adalah gejala depresi, yang didefinisikan sebagai mengalami 4 (empat) dari 6 (enam) kondisi berikut: merasa kesepian, merasa gelisah, kehilangan rasa percaya diri, kesulitan berpikir, merasa cemas sampai tidak bisa tidur di malam hari, dan ingin melakukan bunuh diri, yang diukur melalui wawancara dengan responden (Kuesioner GSHS 2015 No. 34, 38, 39, 40, 82, dan 87) (Kementerian Kesehatan RI. 2015).

Variabel independen utama adalah bullying, kekerasan fisik, dan kekerasan seksual yang pernah dialami dalam tahun ajaran berjalan. Variabel lain sebagai covariat adalah jenis kelamin, tingkat pendidikan SMP vs SMA, Konsumsi alkohol, Konsumsi obat-obatan terlarang, dan Merokok.

Analisis multiple regresi logistik digunakan untuk mengetahui faktor risiko yang berhubungan dengan depresi. Analisis data menggunakan complex samples mempertimbangkan bobot, strata, dan cluster, sesuai dengan desain sampel GSHS yang menggunakan teknik two-stage probability sample (Kementerian Kesehatan RI. 2015).

\section{HASIL DAN PEMBAHASAN}

Karakteristik pelajar SMP dan SMA di Indonesia menurut jenis kelamin, tingkat pendidikan, konsumsi alkohol, obat terlarang, dan rokok, serta pengalaman yang berisiko menyebabkan depresi seperti bully, kekerasan fisik, dan kekerasan seksual adalah sebagai berikut. Jumlah pelajar perempuan lebih banyak (54.6\%) dibandingkan laki-laki. Tiga dari empat pelajar merupakan pelajar yang duduk di bangku SMP (75.5\%). Dalam kurun waktu sebulan terakhir sebelum survei, sebesar $1 \%$ pelajar mengkonsumsi obat-obatan terlarang, sebesar $6.8 \%$ pelajar mengkonsumsi alkohol, sebesar $18,9 \%$ pelajar merokok. Dalam tahun ajaran berjalan, sebesar $18.5 \%$ pelajar

Tabel 1. Gejala Depresi pada Pelajar SMP dan SMA di Indonesia Tahun $2015(n=8,517)$

\begin{tabular}{|c|c|c|}
\hline Gejala Depresi & $\mathrm{n}$ & $\%$ \\
\hline Kesulitan Belajar & 7.538 & 88.5 \\
\hline Merasa Kesepian & 4.868 & 56.5 \\
\hline Sulit Tidur di Malam Hari & 4.453 & 52.0 \\
\hline $\begin{array}{l}\text { Merasa Tidak Berharga atau } \\
\text { Tidak Berguna }\end{array}$ & 2.828 & 32.5 \\
\hline Merasa Takut atau Tidak Aman & 678 & 7.3 \\
\hline Ingin Bunuh Diri & 402 & 4.4 \\
\hline $\begin{array}{l}\text { Mengalami Gejala Depresi* (4 } \\
\text { dari } 6 \text { gejala) }\end{array}$ & 1.843 & 20.7 \\
\hline
\end{tabular}

menjawab 4 jawaban "Ya" dari 6 pertanyaan (kesulitan belajar, merasa kesepian, sulit tidur di malam hari, merasa tidak berharga atau tidak berguna, merasa takut atau tidak aman, atau ingin bunuh diri) mengalami bullying, sebesar $29.4 \%$ pelajar mengalami kekerasan fisik, dan sebesar $3.1 \%$ pelajar mengalami kekerasan seksual.

Berdasarkan gejala depresi, hasil analisis menunjukkan bahwa pelajar SMP dan SMA yang mengalami gejala depresi sebesar 20.7\% (paling sedikit mengalami 4 (empat) dari 6 (enam) gejalan depresi. Gambaran rinci keenam gejala depresi adalah sebagai berikut. Persentase pelajar yang mengalami kesulitan belajar sebesar $88.5 \%$, yang mengalami kesepian sebesar $56.5 \%$, yang mengalami kesulitan tidur di malam hari sebesar $52 \%$, yang merasa tidak berguna atau tidak berharga sebesar 32.5\%, yang merasa takut atau tidak aman sebesar $7.3 \%$, dan yang ingin bunuh diri sebesar $4.4 \%$ (Tabel 1).

Tabel 2 memperlihatkan distribusi gejala depresi pada pelajar SMP dan SMA menurut faktor risikonya. Persentase gejala depresi pada pelajar SMP dan SMA yang mengalami bullying dalam tahun ajaran berjalan sebesar $37 \%$, angka ini jauh lebih tinggi dibandingkan dengan mereka yang tidak mengalami bullying yaitu $17 \%$. Persentase gejala depresi pada 
pelajar SMP dan SMA yang mengalami dibandingkan dengan mereka yang tidak kekerasan fisik dalam tahun ajaran berjalan mengalami kekerasan fisik yaitu $16.7 \%$. sebesar $30.2 \%$, angka ini jauh lebih tinggi

Tabel 2. Efek Bullying, Kekerasan Fisik, Kekerasan Seksual, dan faktor lain terhadap Gejala Depresi pada Pelajar SMP dan SMA di Indonesia Tahun 2015

\begin{tabular}{llllllll}
\hline & Jumla & & & $\mathrm{p}-$ & ORc & $\mathrm{p}-$ & ORa \\
Faktor Risiko & $\mathrm{h}$ & & Gejala Depresi & value $^{+}$ & $(95 \% \mathrm{CI})$ & value $^{++}$ & $\begin{array}{l}(95 \% \mathrm{CI}) \\
\end{array}$ \\
& $\mathrm{n}=8,51$ & & Tidak & Ya & & & \\
& 7 & $\%$ & $(\%)$ & $(\%)$ & & & \\
\hline
\end{tabular}

Mengalami bullying

\begin{tabular}{|c|c|c|c|c|c|c|c|c|c|c|}
\hline & & 81. & & & & & & & & \\
\hline Tidak & 6,940 & $\begin{array}{l}5 \\
18 .\end{array}$ & 83.0 & 17.0 & & $\begin{array}{l}1.0 \\
2.87\end{array}$ & (2.4-- & & 2.51 & (2.1- \\
\hline $\begin{array}{l}\text { Ya } \\
\text { Mengalami } \\
\text { fisik }\end{array}$ & $\begin{array}{c}1,577 \\
\text { kekerasan }\end{array}$ & 5 & 63.0 & 37.0 & $<0.001$ & 3.4) & & $<0.001$ & 3.0) & \\
\hline Tidak & 6,059 & $\begin{array}{l}71 . \\
1 \\
28 .\end{array}$ & 83.3 & 16.7 & & $\begin{array}{l}1.0 \\
2.16\end{array}$ & (1.9-- & & 2.05 & (1.8- \\
\hline Ya & 2,458 & 9 & 69.8 & 30.2 & $<0.001$ & 2.4) & & $<0.001$ & 2.4) & \\
\hline Mengalami & ekerasan sel & 96. & & & & & & & & \\
\hline Tidak & 8,242 & 8 & 79.8 & 20.2 & & $\begin{array}{l}1.0 \\
2.33\end{array}$ & (1.8-- & & 1.76 & (1.4- \\
\hline Ya & 275 & 3.2 & 63.0 & 37.0 & $<0.001$ & 2.9) & & $<0.001$ & 2.3) & \\
\hline
\end{tabular}

Tingkat Pendidikan

\begin{tabular}{|c|c|c|c|c|c|c|c|c|c|}
\hline SMP & 6,031 & $\begin{array}{l}70 . \\
8 \\
29 .\end{array}$ & 82.0 & 18.0 & & $\begin{array}{l}1.0 \\
1.85\end{array}$ & (1.5-- & & 2.05 \\
\hline SMA & 2,486 & 2 & 71.1 & 29.9 & $<0.001$ & 2.3) & & $<0.001$ & 2.6) \\
\hline
\end{tabular}

Jenis kelamin

$\begin{array}{lllllllllll}\text { Laki-laki } & 3,600 & 3 & 82 . & 81.4 & 18.6 & & 1.0 & & & \\ & & 57 . & & & & 1.26 & (1.1-- & & 1.92 & \text { (1.7- } \\ \text { Perempuan } & 4,917 & 7 & 77.6 & 22.4 & 0.012 & 1.4) & & <0.001 & 2.2) & \end{array}$

Mengkonsumsi alkohol

$\begin{array}{lllllllllll}\text { Tidak } & 7,920 & 0 & 83.4 & 19.6 & & 1.0 & & & & \\ & & & & & & & & & & \\ & & & & & & & & & \\ \text { Ya } & 597 & 7.0 & 64.0 & 36.0 & <0.001 & 2.9) & & 0.001 & 2.1) & \end{array}$

Merokok

82.

\begin{tabular}{|c|c|c|c|c|c|c|c|c|}
\hline Tidak & 7,000 & 2 & 80.8 & 19.2 & & 1.0 & & 150 \\
\hline $\mathrm{Ya}$ & 1,517 & 8 & 72.8 & 27.2 & $<0.001$ & 1.9) & 0.001 & 2.0) \\
\hline
\end{tabular}

Mengkonsumsi obat terlarang

\begin{tabular}{|c|c|c|c|c|c|c|c|c|}
\hline \multirow{3}{*}{ Tidak } & \multirow{2}{*}{\multicolumn{2}{|c|}{$\begin{array}{ll}99 . \\
8\end{array}$}} & \multirow[b]{2}{*}{79.5} & \multirow[b]{2}{*}{20.5} & & \multirow{3}{*}{0.507} & \multirow[b]{3}{*}{$\begin{array}{l}1.23 \\
2.3)\end{array}$} \\
\hline & & & & & & \multirow[b]{2}{*}{ (1.7-- } & & \\
\hline & 75 & 0.9 & 56.1 & 43.9 & 0.002 & & & \\
\hline
\end{tabular}


Persentase gejala depresi pada pelajar SMP dan SMA yang mengalami kekerasan seksual dalam tahun ajaran berjalan sebesar 37\%, angka ini jauh lebih tinggi dibandingkan dengan mereka yang tidak mengalami kekerasan seksual yaitu $20.2 \%$

Persentase gejala depresi juga lebih tinggi pada pelajar SMA (29.9\%) dibandingkan pelajar SMP (18\%), lebih tinggi pada perempuan (22\%) dibandingkan laki-laki (18\%), lebih tinggi pada mereka yang mengkonsumsi alkohol (36\%) dibandingkan yang tidak (19.6\%), lebih tinggi pada mereka yang merokok (27.2\%) dibandingkan yang tidak (19.2\%), lebih tinggi pada mereka yang mengkonsumsi obat terlarang (43.9\%) dibandingkan yang tidak (20.5\%).

Analisis multivariabel pada tabel 2 memperlihatkan bahwa remaja SMP dan SMA yang mengalami bullying, kekerasan fisik, dan kekerasan seksual berisiko lebih besar untuk mengalami gejala depresi. Remaja SMP dan SMA yang pernah mengalami bullying dalam tahun ajaran berjalan berisiko 2.5 kali lebih besar mengalami gejala depresi dibandingkan dengan mereka yang tidak pernah mengalami bullying. Remaja SMP dan SMA yang pernah mengalami kekerasan fisik dalam tahun ajaran berjalan berisiko 2.1 kali lebih besar mengalami gejala depresi dibandingkan dengan mereka yang tidak pernah mengalami kekerasan fisik. Remaja SMP dan SMA yang pernah mengalami kekerasan seksual dalam tahun ajaran berjalan berisiko 1.76 kali lebih besar mengalami gejala depresi dibandingkan dengan mereka yang tidak pernah mengalami kekerasan seksual.

Faktor lain yang berisiko lebih besar terhadap munculnya gejala depresi pada pelajar SMP dan SMA adalah jenis kelamin, tingkat pendidikan, minum alkohol, dan merokok. Pelajar perempuan berisiko 1.9 kali lebih besar untuk mengalami gejala depresi dibanding lakilaki. Pelajar SMA berisiko 2 kali lebih besar untuk mengalami gejala depresi dibanding SMP. Pelajar yang minum alkohol berisiko 1.7 kali lebih besar untuk mengalami gejala depresi dibanding yang tidak minum alkohol. Pelajar yang perokok berisiko 1.6 kali lebih besar untuk mengalami gejala depresi yang tidak merokok.
Tidak ada perbedaan risiko yang signifikan untuk timbulnya gejala depresi pada mereka yang mengkonsumsi obat terlarang dengan yang tidak.

\section{Gejala depresi}

Seseorang dikatakan depresi jika memiliki beberapa gejala yang berdampak merugikan pada kondisi fisik, mental, atau sosial. Sebelum masuk pada tahap depresi, penting untuk mendeteksi lebih awal gejala depresi, agar dapat dilakukan intervensi sesegera mungkin, sehingga dampak yang ditimbulkan dapat diminimalisir. Penelitian ini menilai gejala depresi pada pelajar SMP dan SMA di Indonesia serta menilai faktor risiko dari bullying, kekerasan fisik, dan kekerasan seksual terhadap munculnya gejala depresi.

Hasil penelitian ini memperlihatkan bahwa prevalensi gejala depresi pada pelajar SMP dan SMA di Indonesia tahun 2015 sebesar 20,7\%. Angka ini sejalan dengan penelitian yang dilakukan oleh Peltzer dan Pengpid pada populasi dewasa di Indonesia yaitu sebesar 21,8\% (Peltzer, 2018). Angka ini lebih tinggi dari penelitian di Cina, prevalensinya sebesar $15,7 \%$ dan $17,7 \%$ (Hong, 2009) (Wang, 2021). Sementara itu, prevalensi gejala depresi pada pelajar di Indonesia lebih rendah dibandingkan dengan pelajar perempuan di Uganda yaitu sebesar 29\% (Nabunya, 2020). Juga lebih rendah dari prevalensi depresi pada mahasiswa di Jakarta yaitu sebesar 90\% (EL-Matury, 2018). Hal ini memperlihatkan bahwa gejala depresi pada pelajar di Indonesia hampir sama dengan negara lain di dunia. Selain itu, gejala depresi sudah ada sejak pelajar masih duduk di bangku SMP dan SMA, kemudian berlanjut dan makin bertambah besar saat mereka memasuki bangku kuliah, seiring dengan bertambahnya faktor pendorong dan pencetus timbulnya gejala depresi tersebut.

\section{Efek bullying, kekerasan fisik, dan kekerasan seksual terhadap gejala depresi}

Hasil analisis pada penelitian ini, menunjukkan bahwa terdapat hubungan antara bullying dengan gejala depresi pada pelajar SMP dan SMA. Sejalan dengan penelitian yang dilakukan oleh Ramadhani (2013), melaporkan 
adanya hubungan signifikan antara bullying dengan depresi. Semakin sering pelajar mengalami peristiwa bullying maka semakin berat depresi yang dialaminya. Bullying selalu melibatkan pelaku yang lebih kuat dari korban, sehingga sulit bagi korban untuk membela diri, karena tidak mampu membela diri maka korban mungkin merasa tidak berdaya (Ramadhani, 2013). Selain itu, korban bullying mengalami berbagai hambatan, seperti kesejahteraan psikologis yang rendah, perasaan tidak nyaman, merasa takut, rendah diri, merasa tidak berharga, kemampuan beradaptasi sosial yang buruk, takut pergi ke sekolah atau bahkan tidak ingin pergi ke sekolah, menarik diri dari hubungan interpersonal, penurunan prestasi akademik karena sulit berkonsentrasi belajar, dan sampai ingin bunuh diri (Mubasyiroh, 2016).

Pada penelitian ini, hasil analisis menunjukkan bahwa variabel kekerasan fisik dan kekerasan seksual memiliki hubungan yang signifikan dengan gejala depresi. menurut Peltzer (2015), terdapat hubungan antara kekerasan fisik dengan gejala depresi berat (OR: 1,62 ; 95\% CI: 1,29-2,03) (Peltzer, 2015). Penelitian lain yang dilakukan di Indonesia juga menunjukkan hasil yang signifikan antara kekerasan seksual dengan gejala depresi (Dhamayanti, 2020). Pelajar yang mengalami kekerasan baik di rumah maupun di sekolah akan memiliki risiko gangguan depresi (Nalugya-Sserunjogi, 2016). Kekerasan di sekolah memainkan peran penting dalam mengembangkan depresi (Dhamayanti, 2020). Riwayat kekerasan seksual terhadap anak dapat menyebabkan gangguan kesehatan mental, seperti depresi, psikosis, kecemasan dan gangguan pasca-trauma (Dhamayanti, 2020).

Faktor lain yang berhubungan dengan tingginya risiko mengalami gejala depresi adalah jenis kelamin perempuan, duduk dibangku SMA, konsumsi alkohol dan rokok. Pada penelitian ini pelajar yang berjenis kelamin perempuan lebih berisiko mengalami gejala depresi 1.92 kali lebih tinggi dibandingkan lakilaki. Sejalan dengan penelitian lain, perempuan lebih tinggi untuk mengalami gejala depresi dibandingkan laki-laki (Desi, 2020). Hasil serupa ditemukan di Jamaica (Ekundayo, 2007) dan di Sweden (Wirback, 2014). Hal tersebut terjadi karena perempuan biasanya lebih sensitif dibandingkan laki-laki. Suasana hati yang mudah berubah-ubah (faktor hormonal) sering dialami perempuan saat menstruasi (Desi, 2020). Disarankan kepada Kementerian Pendidikan agar menerapkan sekolah ramah anak untuk mengurangi kejadian bullying dan kekerasan fisik atau kekerasan seksual pada pelajar, yang dapat berisiko menimbulkan gejala depresi, terutama pada pelajar perempuan dan level SMA.

Hasil penelitian menunjukkan pelajar SMA lebih berisiko untuk mengalami gejala depresi (OR: 2,05 ; 95\% CI: 1,6-2,6). Sejalan dengan hasil penelitian yang dilakukan di Cina, menunjukkan bahwa pelajar yang duduk dibangku SMA lebih berisiko untuk mengalami gejala depresi dengan nilai OR yaitu 3,25 (Tan, 2018). Penelitian yang dilakukan di Korea Selatan juga menunjukkan hasil yang sama. Pelajar SMA lebih berisiko untuk mengalami depresi karena mereka berada di bawah tekanan saat mempersiapkan ujian masuk universitas, khususnya kelas 12 (Park et al, 2012). Selain itu, semakin tinggi tingkat pendidikan seseorang biasanya semakin banyak tekanan yang dialami. Sejalan dengan penelitian di Jakarta bahwa pada mahasiswa prevalensi kejadian depresi sebesar 90\% (EL-Matury, 2018).

Hasil analisis menunjukkan bahwa konsumsi alkohol memiliki hubungan yang signifikan dengan gejala depresi. Sejalan dengan hasil penelitian lain, menunjukkan bahwa terdapat hubungan yang signifikan antara konsumsi alkohol dengan gejala depresi (Hong, 2009). Penelitian yang dilakukan di Uganda juga menunjukkan adanya hubungan konsumsi alkohol dengan gejala depresi (OR: 1,76; 95\% CI: 0,9-3,4) (Nalugya, 2016). Sementara penelitian yang dilakukan di Norwegian menunjukkan tingkat gejala depresi yang lebih tinggi dikaitkan dengan penggunaan alkohol yang lebih awal, konsumsi yang lebih sering, dan keracunan (intoxications) (Johannessen, 2017). Dalam jangka pendek menunjukkan 
bahwa penggunaan atau penyalahgunaan alkohol dapat menyebabkan depresi, karena efek farmakologis dari alkohol (Coelho, 2014). Sedangkan dalam jangka panjang, depresi dapat terjadi akibat atrofi hipokampus (Coelho, 2014).

Hasil analisis menunjukkan bahwa ada hubungan yang signifikan antara perilaku merokok dengan depresi, nilai OR sebesar 2,69 $(95 \%$ CI $=1,80-4,03)$. Penelitian lain juga menunjukkan adanya hubungan antara perilaku merokok dengan gejala depresi (Acartürk, 2011). Selain itu, merokok dapat berkontribusi terjadinya depresi atau sebaliknya yaitu sebagai koping stress (Christiani, 2015). Merokok dapat menjadi metode pengobatan sendiri untuk mengatasi masalah mental, karena asap rokok dapat bertindak secara farmakologis di otak yang mirip dengan obat antidepresan (Liew, 2015).

Pada penelitian yang dilakukan di Uganda diketahui bahwa terdapat hubungan antara penggunaan narkoba dengan gejala depresi (Nalugya, 2016). Oleh karena data yang digunakan adalah cross sectional maka tidak dapat menyimpulkan apakah penggunaan narkoba dapat menyebabkan gejala depresi atau sebaliknya gejala depresi menyebabkan penggunaan narkoba (Nalugya, 2016).

\section{PENUTUP}

Prevalensi gejala depresi pada pelajar SMP dan SMA di Indonesia pada tahun 2015 sebesar 20,7\%. Dalam tahun ajaran berjalan, sebesar $18.5 \%$ pelajar mengalami bullying, sebesar $29.4 \%$ pelajar mengalami kekerasan fisik, dan sebesar $3.1 \%$ pelajar mengalami kekerasan seksual. Hasil analisis memperlihatkan remaja yang mengalami bullying, kekerasan fisik, dan kekerasan seksual berisiko lebih tinggi mengalami gejala depresi. ORa bullying sebesar 2.5, ORa kekerasan fisik sebesar 2.1, dan ORa kekerasan seksual sebesar 1.8. Faktor lain yang memiliki risiko lebih tinggi untuk mengalami gejala depresi adalah jenis kelamin perempuan (ORa 1.9), pendidikan SMA (ORa 2.1) dibanding SMP, minum alkohol (ORa 1.7), dan merokok (ORa 1.6).
Disarankan kepada Kementerian Pendidikan agar menerapkan sekolah ramah anak untuk mengurangi kejadian bullying dan kekerasan fisik atau kekerasan seksual pada pelajar, yang dapat berisiko menimbulkan gejala depresi, terutama pada pelajar perempuan dan level SMA.

\section{DAFTAR PUSTAKA}

Acartürk, C., Nierkens, V., Agyemang, C., et al. 201). Depressive symptoms and smoking among young Turkish and Moroccan ethnic minority groups in the Netherlands: a cross-sectional study. Substance Abuse Treatment, Prevention, and Policy, 6(5).

Christiani, Y., Byles, J., Tavener, M., et al. 2015. Socioeconomic related inequality in depression among young and middle-adult women in Indonesia's major cities. Journal of Affective Disorders, 182: 76-81.

Coelho, C., Laranjeira, R., Santos, J., et al. 2014. Depressive symptoms and alcohol correlates among Brazilians aged 14 years and older: a cross-sectional study. Substance Abuse Treatment, Prevention, and Policy, 9(29).

Desi, Felita, A., Kinasih, A. 2020. Gejala Depresi Pada Remaja di Sekolah Menengah Atas. Jurnal Ilmiah Ilmu Kesehatan, 8(1).

Dhamayanti, M., Noviandhari, A., Masdiani, N., et al. 2020. The association of depression with child abuse among Indonesian adolescents. BMC Pediatrics, 20(313).

EL-Matury, H., Lestari, F., dan Besral. 2018. Depression, Anxiety and Stress among Undergraduate Students in Jakarta: Examining Scores of the Depression Anxiety and Stress Scale According to Origin and Residency. Indian Journal of Public Health Research \& Development, 9(2).

EL-Matury, H., Lestari, F., dan Besral. 2021. Structural Equation Model Factors Affecting Suicidal Ideation among Undergraduate Students. European Journal of Molecular \& Clinical Medicine, 8(3).

Hong, X., Li, J., Xu, F., et al. 2009. Physical activity inversely associated with the presence of depression among urban adolescents in regional China. BMC Public Health, 9(148).

Indarto, W. 2017. DEPRESI PADA ANAK - IDAI Ikatan Dokter Anak Indonesia. [internet] Idaijogja.or.id. Available at: 
$<$ http://www.idaijogja.or.id/depresi-padaanak $/>$.

Iskandarsyah, A. 2006. Remaja dan Permasalahannya: Perspektif Psikologi Terhadap Permasalahan Remaja dalam Bidang Pendidikan. Jatinangor: Universitas Padjajaran, dalam Rahayu, A., Noor, M., Yulidasari, F., et al. 2017. Buku Ajar Kesehatan Reproduksi Remaja dan Lansia. 1st ed. Surabaya: Airlangga University Press, p.5.

Johannessen, E., Andersson, H., Bjørngaard, J. and Pape, K. 2017. Anxiety and depression symptoms and alcohol use among adolescents - a cross sectional study of Norwegian secondary school students. BMC Public Health, 17(494).

Kementerian Kesehatan Republik Indonesia. 2018. Hasil Utama Riskesdas 2018. Jakarta: Badan Penelitian dan Pengembangan Kesehatan RI.

Kementerian Kesehatan Republik Indonesia. 2013. Riset Kesehatan Dasar Riskesdas 2013. Jakarta: Badan Penelitian dan Pengembangan Kesehatan RI.

Kementerian Pendidikan dan Kebudayaan. 2017. Indonesia Educational Statistics In Brief. Jakarta.

Liew, H. dan Gardner, S. 2015. The interrelationship between smoking and depression in Indonesia. Health Policy and Technology, 5: 2631.

Mubasyiroh, R., Putri, I., Tjandrarini, D. 2016. Determinan Gejala Mental Emosional Pelajar SMP-SMA di Indonesia Tahun 2015. Buletin Penelitian Kesehatan, 45(2).

Nabunya, P., Damulira, C., Byansi, W., et al. 2020. Prevalence and correlates of depressive symptoms among high school adolescent girls in southern Uganda. BMC Public Health, 20(1792).

Nalugya-Sserunjogi, J., Rukundo, G., Ovuga, E., et al. 2016. Prevalence and factors associated with depression symptoms among school-going adolescents in Central Uganda. Child Adolesc Psychiatry Ment Health, 10(39).

Park, H., Heo, J., Subramanian, S., et al. 2012. Socioeconomic Inequalities in Adolescent Depression in South Korea: A Multilevel Analysis. PLoS ONE, 7(10).

Peltzer, K. and Pengpid, S. 2015. Depressive symptoms and social demographic, stress and health risk behaviour among university students in 26 low-, middle- and high-income countries. International Journal of Psychiatry in Clinical Practice, 19: 260-266.

Peltzer, K. and Pengpid, S. 2018. High prevalence of depressive symptoms in a national sample of adults in Indonesia: Childhood adversity, sociodemographic factors and health risk behaviour. Asian Journal of Psychiatry, 33: 5259.

Pereira-Miranda, E., Costa, P., Queiroz, V., et al. 2017. Overweight and Obesity Associated with Higher Depression Prevalence in Adults: A Systematic Review and MetaAnalysis. Journal of the American College of Nutrition, 36(3): 223-233.

Rahayu, A., Noor, M., Yulidasari, F., et al. 2017. Buku Ajar Kesehatan Reproduksi Remaja dan Lansia. 1st ed. Surabaya: Airlangga University Press, p.5.

Ramadhani, A., dan Retnowati, S. 2013. Depresi Pada Remaja Korban Bullying. Jurnal Psikologi, 9(2).

Saputri, I., Nurrahima, A. 2020. Faktor-Faktor yang Mempengaruhi Depresi Anak Usia Sekolah: Kajian Literatur. Journal of Holistic Nursing and Health Science, 3(2).

Soetjiningsih. 2011. Tumbuh Kembang Remaja dan Permasalahannya. Jakarta: CV Sagung, dalam Desi, Felita, A., Kinasih, A. 2020. Gejala Depresi Pada Remaja di Sekolah Menengah Atas. Jurnal Ilmiah Ilmu Kesehatan, 8(1).

Sulistyorini, W., Sabarisman, M. 2017. Depresi: Suatu Tinjauan Psikologis. Jurnal Sosio Informa, 3(2).

Tan, M., Chen, M., Li, J., et al. 2018. Depressive symptoms and associated factors among leftbehind children in China: a cross-sectional study. BMC Public Health, 18(1059).

Wang, J., Wang, H., Lin, H., et al. 2021. Study problems and depressive symptoms in adolescents during the COVID-19 outbreak: poor parent-child relationship as a vulnerability. Globalization and Health, 17(40).

Widakdo, G., Besral. 2013. Efek Penyakit Kronis terhadap Gangguan Mental Emosional. Jurnal Kesehatan Masyarakat Nasional, 7(7).

Wirback, T., Möller, J., Larsson, J., et al. 2014. Social factors in childhood and risk of depressive symptoms among adolescents - a longitudinal study in Stockholm, Sweden. International Journal for Equity in Health, 13(96).

World Health Organization. 2016. Adolescents and mental health. [internet] Available at: 
$<$ https://www.who.int/maternal_child_adole scent/topics/adolescence/mental_health/en/ $>$.

Who.int. no date. Adolescent health. [internet] Available

$<$ https://www.who.int/southeastasia/healthtopics/adolescent-health>.

Who.int. no date. Constitution. [internet] Available at: $<$ https://www.who.int/about/who-weare/constitution>.

Who.int. no date. Depression. [internet] Available at: $<$ https://www.who.int/healthtopics/depression\#tab=tab_1>.

Who.int. no date. WHO | Gender and human rights. [internet] Available at $<$ https://www.who.int/reproductivehealth/t opics/gender_rights/sexual_health/en/>.
WHO. (2017a. Depression and other common mental disorders: global health estimates. World Health Organization. https://apps.who.int/iris/handl e/10665/254610. License: CC BY-NC-SA 3.0 IGO

WHO. 2017b. Mental Health Status of Adolescents in South-East Asia : Evidence for Action, Searo. Available

at: https://apps.who.int/iris/bitstream/handle/1 0665/254982/9789290225737-

eng.pdf\%0Ahttp://apps.who.int/iris/bitstrea $\mathrm{m} / 10665 / 254982 / 1 / 9789290225737$ eng.pdf?ua $=1 \& u a=1 \& u a=1 \& u a=1$.

Who.int. no date. 10 facts on mental health. [inernet] Available at: <https://www.who.int/newsroom/facts-in-pictures/detail/mental-health>. 